\title{
Isolation and Detection of Vibrio vulnificus from Coastal Seawater of
}

\section{Babolsar}

\author{
Majid Alipour (ib) ${ }^{1,}$, Reza Mirabbasi ${ }^{1}$, Issa Gholampour Azizi ${ }^{1}$ and Yousef Yahyapour ${ }^{2}$ \\ ${ }^{1}$ Department of Microbiology, Babol Branch, Islamic Azad University, Babol, Iran \\ ${ }^{2}$ Department of Microbiology, Infectious Diseases and Tropical Medicine Research Center, Faculty of Medicine, Babol University of Medical Sciences, Babol, Iran \\ "Corresponding author: Department of Microbiology, Babol Branch, Islamic Azad University, Babol, Iran. Tel: +98-9111146105, Email: m.alipourkabria46@gmail.com
}

Received 2018 February 01; Revised 2018 April 25; Accepted 2018 May 15.

\begin{abstract}
Background: Vibrio (v.) vulnificus strains are a human pathogenic bacteria that reside innately in coastal seawaters and shellfish. The bacteria can cause severe skin infections and quickly develop a lethal septicemia in immunocompromised individuals, who have eaten raw shellfish.

Objectives: The goal of this investigation was to define the prevalence of $V$. vulnificus in seawater samples collected from coastal seawaters.

Methods: Three hundred seawater specimens were prepared during spring and summer. Isolated bacteria were confirmed by the polymerase chain reaction (PCR) technique and by sequencing of PCR products.

Results: The PCR technique of 276 presumptive V. vulnificus isolates showed two (0.72\%) positive amplifications of the gyrB gene. Vibrio vulnificus was isolated from specimens collected during the summer months.

Conclusions: In the present investigation, the presence of V. vulnificus was confirmed in the coastal waters of Babolsar. Owing to the existence of the bacteria in the coastal water of Babolsar, it appears that swimming with an open wound during summer can result in skin infection and sepsis.
\end{abstract}

Keywords: Vibrio vulnificus, PCR, Seawater

\section{Background}

Vibrio vulnificus strains are halophilic, motile, curved, gram-negative bacteria that exist in coastal waters worldwide and are a commensal bacteria in shellfish and fish (1). The bacteria is positive oxidase (2). The strains of $V$. vulnificus are divided to three biotypes. All biotypes of $V$.vulnificus are pathogenic for humans. Biotype 1 is the most prevalent cause of septicemia (3). The number of culturable V.vulnificus strains typically decreases by reducing water temperature. In this condition (water temperature below $15^{\circ} \mathrm{C}$ ), the bacteria may enter a viable but non-culturable (VBNC) step. The highest densities are observed during the warm months. Salinity influences the numbers of culturable $V$. vulnificus, as the highest densities are generally detected at salinities between $5 \%$ and $25 \%$ (4). Roland et al. introduced the first clinical case of $V$. vulnificus infection in 1970 (5). In addition, the first wound infection created by $\mathrm{V}$. vulnificus was reported in 1979 by Blake et al. (6). Ingestion of raw or inadequately cooked seafood containing $V$. vulnificus can lead to sepsis. The signs and symptoms of sepsis caused by these bacteria involve fever, chills, nausea, endotoxic shock, and the development of secondary wounds on the extremities of patients. Mortality rates have been re- ported as greater than $50 \%$ in patients with primary sepsis, and about $25 \%$ for wound infections. Wound infections progress quickly to cellulitis, ecchymoses, and bullae, which can lead to necrotizing cellulitis and even secondary sepsis at the site of infection $(7,8)$. The virulence factors of $V$. vulnificus include resistance to stomach acid, capsule, endotoxin, cytotoxins, pilus, and flagellum $(8,9)$. Several PCR assays have been designed for diagnosis of $V$. vulnificus yet were unable to find $V$. vulnificus strains. Therefore, the gyrB gene was chosen for detection of $V$. vulnifcus as previously described by Kumar et al. (10). This gene codes the B subunit of the gyrase, which removes positive supercoils during DNA replication (10). Up to now, no investigation has been done on the prevalence of the bacteria in coastal water of Babolsar. Babolsar is one of the coastal cities of the Mazandaran province (north of Iran). The goal of this investigation was to define the prevalence of $\mathrm{V}$. vulnificus in seawater samples, collected from coastal waters of Babolsar by the PCR method. 


\section{Methods}

\subsection{Isolation of Vibrio vulnificus}

Three hundred (300) coastal seawater specimens were taken during the spring and summer of 2017. The sample size was determined by the Morgan table. The reason to choose spring and summer for the study was that increasing temperature leads to higher salinity water; therefore, bacteria isolation will be possible. Seawater samples were added, at a depth of $50 \mathrm{~cm}$, to sterile bottles. In sampling, water temperature was measured using a thermometer. Samples were processed within six hours of sampling. To isolate V. vulnificus from seawater, 25-mL samples were added to $225 \mathrm{~mL}$ of peptone water and kept at $37^{\circ} \mathrm{C}$ for six hours. Ten microliters of the cell suspension were then transferred onto thiosulfate citrate bile sucrose (TCBS) agar and incubated at $37^{\circ} \mathrm{C}$ for 24 hours. Suspected colonies of $\mathrm{V}$. vulnificus (green colonies) were picked from the plates and identified by PCR $(11,12)$.

\subsection{DNA Extraction}

DNA extraction was accomplished by the boiling method. In total, $1.5 \mathrm{~mL}$ of an overnight culture of $\mathrm{V}$. vulnificus was centrifuged at $6000 \mathrm{rpm}$ for five minutes. The cell pellet was suspended in $300 \mu$ L of TE buffer (10 mM Tris$\mathrm{HCl}, 0.5 \mathrm{mM}$ EDTA, pH 8), boiled for 10 minutes, and subsequently cooled on ice for five minutes. After incubation on ice, the tube was centrifuged at 10,000 rpm for 5 minutes at $4{ }^{\circ} \mathrm{C}$. The supernatant $(200 \mu \mathrm{L})$ was added to a fresh sterile tube and stored at $-20^{\circ} \mathrm{C}$ for long preservation (13).

\subsection{Confirmation of Vibrio vulnificus by the Polymerase Chain Reaction}

Confirmation of all $V$. vulnificus strains was performed on all of the green colonies that appeared on TCBS Agar by the PCR technique, as formerly reported by Kumar et al. in 2006. Due to unavailability of a positive control, detection was done via sequencing of PCR products. The PCR products were sequenced by Bioneer corporation. The primers were used for the amplification of a 285-base pair (bp) part of $V$. vulnificus gyrB gene (10). Table 1 shows the sequence of primers employed for the current investigation.

The PCRs were performed in a final volume of $20 \mu \mathrm{L}$. The reaction mixture included $2 \mu \mathrm{L}$ of DNA template, $2 \mu \mathrm{L}$ of 10x PCR buffer, $0.4 \mu \mathrm{L}$ of deoxynucleoside triphosphates (10 mM), $0.6 \mu \mathrm{L}$ of $50 \mathrm{mM} \mathrm{MgCl} 2,0.2 \mu \mathrm{L}$ of Taq DNA polymerase ( $5 \mathrm{U}), 0.5 \mu \mathrm{L}$ of each primer (20 pmol), and $10.8 \mu \mathrm{L}$ of distilled water. Initial denaturation at $94^{\circ} \mathrm{C}$ for $5 \mathrm{~min}$ utes, followed by 30 cycles of denaturation at $94^{\circ} \mathrm{C}$ for 30 seconds, annealing at $60^{\circ} \mathrm{C}$ for 30 seconds, and extension at $72{ }^{\circ} \mathrm{C}$ for 30 seconds. The final extension was done at $72^{\circ} \mathrm{C}$ for five minutes (12). Gel electrophoresis of PCR products was accomplished on a $2 \%$ agarose gel and observed by UV transilluminator after ethidium bromide (EtBr) staining. Data were analyzed by the SPSS software version 16 .

\section{Results}

Vibrio vulnificus creates green colonies on the TCBS agar. Of 300 seawater samples, $276 \mathrm{~V}$. vulnificus presumptive green colonies were grown on TCBS agar plates. Gel electrophoresis of PCR products generated a 285-bp segment corresponding to the gyrB gene (Figure 1).

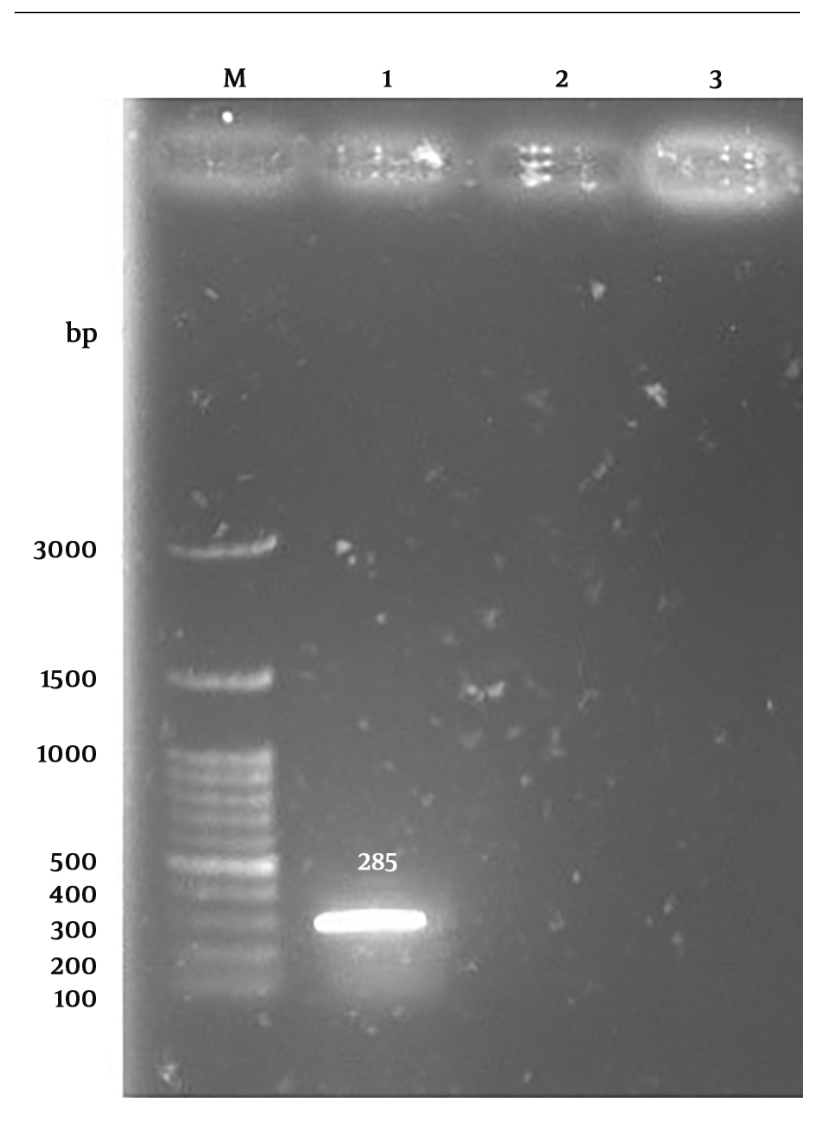

Figure 1. Agarose gel electrophoresis of polymerase chain reaction products, Lane M, DNA ladder; Lane 1, positive sample; Lane 2, negative sample; Lane 3, negative control

To establish the accuracy of the primers, the PCR product was sequenced using forward and reverse primers. Thereafter, the sequences were aligned with the corresponding region of nucleotide sequence, accessible on the GenBank database with accession number: NC_005139.1. The basic local alignment search tool (BLAST) analysis revealed that the PCR product derived from the $V$. vulnificus sequence showed similarity of $94 \%$ with the GenBank gyrB sequence. Therefore, $V$. vulnificus was detected (Figure 2). 


\begin{tabular}{lccrr}
\hline Table 1. The Sequence of Primers Used in the Current Investigation & & \\
\hline Target Organism & Target Gene & Primer Sequence $\left(\mathbf{5}^{\prime}-\mathbf{3}^{\prime}\right)$ & Size of Product (bp) \\
\hline V. vulnificus & gyrB & F-GTCCGCAGTGGAATCCTTCA & Reference \\
& & R-TGGTTCTTACGGTTACGGCC & Kumar et al, 2006 (10) \\
\hline
\end{tabular}

Sequence ID: Query_149219 Length: 285 Number of Matches: 1

Range 1: 1 to 241 Graphics

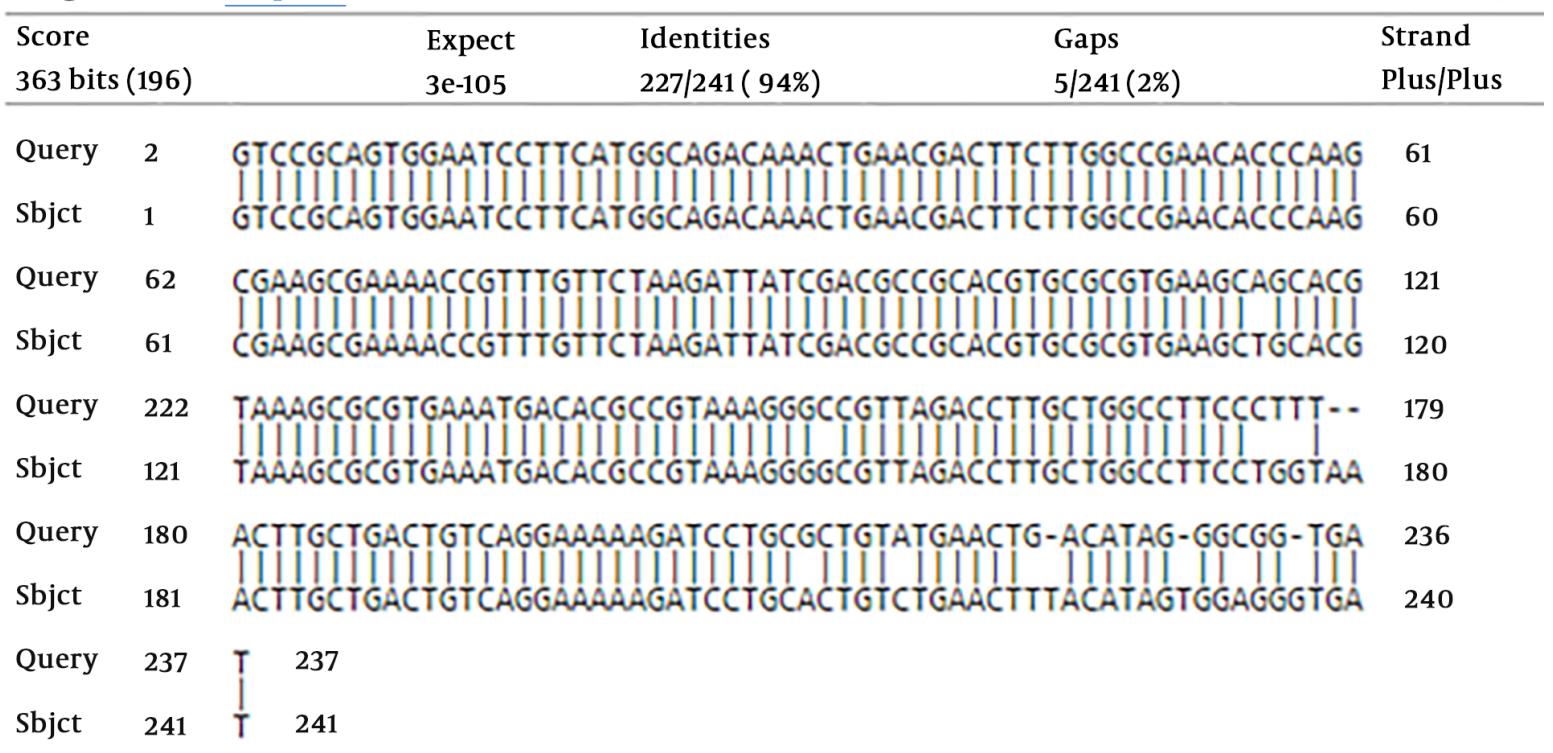

Figure 2. Blast analysis of the polymerase chain reaction product with the corresponding sequence found on GenBank

The results of the PCR technique showed two (0.72\%) positive amplifications of the gyrB gene from 276 the presumptive $V$. vulnificus isolates. Vibrio vulnificus was not detected in any specimens collected during March, April, and May (average water temperature of $15^{\circ} \mathrm{C}$ ) yet was observed in water samples collected during summer (average water temperature of $25^{\circ} \mathrm{C}$ ).

\section{Discussion}

Vibrio vulnificus enters the body via the consumption of seafood or through an open wound exposed to seawater, contaminated with the bacteria. Due to its high proliferation, wound infections may quickly progress to necrotizing fasciitis and septicemia (14). The investigation was done to gain public awareness of bacteria existence in the area under study. This study was the first investigation in relation to the isolation and molecular detection of bacteria in the coastal seawater of Babolsar, northern Iran. Shaw et al. (15) reported that $V$. vulnificus strains were detected from the total sampling sites in the Chesapeake Bay and Maryland Coastal Bays. In a study performed by Paydar and Thong (12), a prevalence of $23 \%$ of V. vulnificus was reported from seawater in Kuala Lumpur, Malaysia. In another study conducted by Rodgers et al. (16) in Colombia, $V$. vulnificus was detected in $11 \%$ of seawater samples. Maugeri et al. (17) showed low incidence of V. vulnificus strains in the Mediterranean Sea. There are reports of the isolation of V. vulnificus strains from fish, shrimp, and crab in the Persian Gulf (18). In current study, two (0.72\%) isolates were identified as V. vulnificus strains by the PCR method. Different results could be due to the levels of contamination of area under study. Furthermore, because of low salinity of Caspian Sea, isolation of the bacteria was lower than other studies performed in other seas. The abundance of $V$. vulnificus in coastal waters was highly correlated with the water temperature. The isolation of culturable forms was done in the warm months of the summer. Maugeri et al. isolated $V$. vulnificus from the water at the temperature range of 20 to $21.5^{\circ} \mathrm{C}(17)$. In this study, the bacteria were 
isolated in summer (mean water temperature of $25^{\circ} \mathrm{C}$ ). It seems that the findings could show the association of the culturable forms with high water temperature. In the current research, $V$. vulnificus was not isolated from specimens obtained during spring. In the Gulf of Mexico, V. vulnificus was not isolated when seawater temperature was under $18^{\circ} \mathrm{C}(19)$. In the study conducted by Pfeffer et al., the bacteria were not isolated at water temperatures below $14^{\circ} \mathrm{C}$ (20). When the water temperatures reach below $13^{\circ} \mathrm{C}, \mathrm{V}$. vulnificus strains enter the VBNC state, in which bacteria are metabolically active yet don't grow on conventional culture media $(21,22)$. In conclusion, due to the presence of $V$. vulnificus in the area under study, the bacteria may be dangerous to swimmers, who have open wounds. Of the limitations of the present research were the high mortality rate of the bacteria. Moreover, the sampling should be performed in the warm seasons, when the water temperature exceeds above $20^{\circ} \mathrm{C}$. Regarding the transmission of $V$. vulnificus, which can occur via fish consumption, it is recommended that a study should be carried out on the presence of the bacteria in fish of the Caspian Sea.

\section{Footnotes}

Authors' Contribution: Majid Alipour collected the data, set up the tests, wrote the manuscript, and performed the interpretation of the results; Reza Mirabbasi Bahnamiri performed the practical experiments and collected the samples; Yousef Yahyapour and Issa Gholampour Azizi contributed to the performing of the experiments and writing of the manuscript; All authors read and approved the final manuscript.

Ethical Considerations: In this paper, there is no research on humans or animals.

Funding/Support: This work was funded through a grant provided by Babol Branch, Islamic Azad University.

\section{References}

1. Lee TH, Kim MH, Lee CS, Lee JH, Rhee JH, Chung KM. Protection against Vibrio vulnificus infection by active and passive immunization with the C-terminal region of the RtXA1/MARTXVv protein. Vaccine. 2014;32(2):271-6. doi: 10.1016/j.vaccine.2013.11.019. [PubMed: 24252692].

2. Haq SM, Dayal HH. Chronic liver disease and consumption of raw oysters: A potentially lethal combination-a review of Vibrio vulnificus septicemia. Am J Gastroenterol. 2005;100(5):1195-9. doi: 10.1111/j.15720241.2005.40814.x. [PubMed: 15842598].

3. Phippen BL, Oliver JD. Clinical and environmental genotypes of Vibrio vulnificus display distinct, quorum-sensing-mediated, chitin detachment dynamics. Pathog Dis. 2015;73(8):ftv072. doi: 10.1093/femspd/ftv072. [PubMed: 26377182]. [PubMed Central: PMC4626603].

4. Chase E, Young S, Harwood VJ. Sediment and vegetation as reservoirs of Vibrio vulnificus in the Tampa Bay Estuary and Gulf of Mexico.
Appl Environ Microbiol. 2015;81(7):2489-94. doi: 10.1128/AEM.03243-14. [PubMed: 25636843]. [PubMed Central: PMC4357930].

5. Zhao $\mathrm{H}, \mathrm{Xu} \mathrm{L}$, Dong $\mathrm{H}, \mathrm{Hu}$ J, Gao H, Yang $\mathrm{M}$, et al. Correlations between clinical features and mortality in patients with Vibrio vulnificus infection. PLoS One. 2015;10(8). e0136019. doi: 10.1371/journal.pone.0136019. [PubMed: 26274504]. [PubMed Central: PMC4537211].

6. Oliver JD. Wound infections caused by Vibrio vulnificus and other marine bacteria. Epidemiol Infect. 2005;133(3):383-91. doi: 10.1017/S0950268805003894. [PubMed: 15962544]. [PubMed Central: PMC2870261].

7. Jones MK, Oliver JD. Vibrio vulnificus: Disease and pathogenesis. Infect Immun. 2009;77(5):1723-33. doi: 10.1128/IAI.01046-08. [PubMed: 19255188]. [PubMed Central: PMC2681776].

8. Horseman MA, Surani S. A comprehensive review of Vibrio vulnificus: an important cause of severe sepsis and skin and soft-tissue infection. Int J Infect Dis. 2011;15(3):e157-66. doi: 10.1016/j.ijid.2010.11.003. [PubMed: 21177133]

9. Chiang SR, Chuang YC. Vibrio vulnificus infection: Clinical manifestations, pathogenesis, and antimicrobial therapy.J Microbiol Immunol Infect. 2003;36(2):81-8. [PubMed: 12886957].

10. Kumar HS, Parvathi A, Karunasagar I, Karunasagar I. A gyrB-based PCR for the detection of Vibrio vulnificus and its application for direct detection of this pathogen in oyster enrichment broths. Int J Food Microbiol. 2006;111(3):216-20. doi: 10.1016/j.ijfoodmicro.2006.05.007. [PubMed: 16854484].

11. Collin B, Rehnstam-Holm AS. Occurrence and potential pathogenesis of Vibrio cholerae, Vibrio parahaemolyticus and Vibrio vulnificus on the South Coast of Sweden. FEMS Microbiol Ecol. 2011;78(2):306-13. doi: 10.1111/j.1574-6941.2011.01157.x. [PubMed: 21692819].

12. Paydar M, Thong KL. Prevalence and genetic characterization of Vibrio vulnificus in raw seafood and seawater in Malaysia. I Food Prot. 2013;76(10):1797-800. doi: 10.4315/0362-028X.JFP-13-141. [PubMed: 24112583].

13. Bier N, Schwartz K, Guerra B, Strauch E. Survey on antimicrobial resistance patterns in Vibrio vulnificus and Vibrio cholerae non-O1/non-O139 in Germany reveals carbapenemase-producing Vibrio cholerae in coastal waters. Front Microbiol. 2015;6:1179. doi: 10.3389/fmicb.2015.01179. [PubMed: 26579088]. [PubMed Central: PMC4623411]

14. Bier N, Jackel C, Dieckmann R, Brennholt N, Boer SI, Strauch E. Virulence profiles of Vibrio vulnificus in German coastal waters, a comparison of North Sea and Baltic Sea isolates. Int J Environ Res Public Health. 2015;12(12):15943-59. doi: 10.3390/ijerph121215031. [PubMed: 26694432]. [PubMed Central: PMC4690967].

15. Shaw KS, Rosenberg Goldstein RE, He X, Jacobs JM, Crump BC, Sapkota AR. Antimicrobial susceptibility of Vibrio vulnificus and Vibrio parahaemolyticus recovered from recreational and commercial areas of Chesapeake Bay and Maryland Coastal Bays. PLoS One. 2014;9(2). e89616. doi: 10.1371/journal.pone.0089616. [PubMed: 24586914]. [PubMed Central: PMC3934932].

16. Rodgers C, Parveen S, Chigbu P, Jacobs J, Rhodes M, Harter-Dennis J. Prevalence of Vibrio parahaemolyticus, and Vibrio vulnificus in blue crabs (Callinectes sapidus), seawater and sediments of the Maryland Coastal Bays. J Appl Microbiol. 2014;117(4):1198-209. doi: 10.1111/jam.12608. [PubMed: 25066367].

17. Maugeri TL, Carbone M, Fera MT, Gugliandolo C. Detection and differentiation of Vibrio vulnificus in seawater and plankton of a coastal zone of the Mediterranean Sea. Res Microbiol. 2006;157(2):194-200. doi: 10.1016/j.resmic.2005.06.007. [PubMed: 16129581].

18. Elmahdi S, DaSilva LV, Parveen S. Antibiotic resistance of Vibrio parahaemolyticus and Vibrio vulnificus in various countries: A review. Food Microbiol. 2016;57:128-34. doi: 10.1016/j.fm.2016.02.008. [PubMed: 27052711]. 
19. Wright AC, Hill RT, Johnson JA, Roghman MC, Colwell RR, Morris JJ Distribution of Vibrio vulnificus in the Chesapeake Bay. Appl Environ Microbiol.1996;62(2):717-24. [PubMed: 8593075]. [PubMed Central: PMC167840].

20. Pfeffer CS, Hite MF, Oliver JD. Ecology of Vibrio vulnificus in estuarine waters of eastern North Carolina. Appl Environ Microbiol. 2003;69(6):3526-31. doi: 10.1128/AEM.69.6.3526-3531.2003. [PubMed: 12788759]. [PubMed Central: PMC161514].

21. Nowakowska J, Oliver JD. Resistance to environmental stresses by
Vibrio vulnificus in the viable but nonculturable state. FEMS Microbiol Ecol. 2013;84(1):213-22. doi: 10.1111/1574-6941.12052. [PubMed: 23228034].

22. Wu B, Liang W, Kan B. Growth phase, oxygen, temperature, and starvation affect the development of Viable but nonculturable state of vibrio cholerae. Front Microbiol. 2016;7:404 doi: 10.3389/fmicb.2016.00404. [PubMed: 27065970]. [PubMed Central: PMC4811941]. 